\title{
METODOLOGIAS ATIVAS: UM RELATO SOBRE APRENDIZAGEM BASEADA EM PROBLEMAS NO ENSINO DE CIÊNCIAS
}

\author{
METODOMELOGICAS ACTIVAS: UN INFORME SOBRE EL APRENDIZAJE \\ BASADO EN PROBLEMAS EN LA CIENCIA
}

\section{ACTIVE METHODOLOGIES: A REPORT ON LEARNING BASED ON PROBLEMS IN SCIENCE TEACHING}

RESUMO: As metodologias ativas estão crescentes no processo de ensino e aprendizagem. Esse cenário, fruto da inserção das TIC em sala de aula. Nesta resenha, verificou-se a Aprendizagem Baseada em Problemas, a qual possui metas de ensinar sobre como e para que serve o tratamento de água, de efluente e de lodos. As metodologias ativas contribuem no processo de formação tanto do discente quanto do docente.

PALAVRAS-CHAVE: Ensino-aprendizagem. Metodologia ativa. Ensino de ciências. Aprendizagem baseada em problemas.

RESUMEN: Las metodologías activas están creciendo en el proceso de enseñanza y aprendizaje. Este escenario es el resultado de la inserción de las TIC en el aula. En esta revisión, verificamos el aprendizaje basado en problemas, que tiene metas que enseñar sobre cómo y para el tratamiento del agua, los efluentes y los lodos. Las metodologías activas contribuyen al proceso de formación tanto de los estudiantes como de los profesores.

PALABRAS CLAVE: Enseñanza-aprendizaje. Metodología activa. Enseñanza de ciencias. Aprendizaje basado en problemas.

ABSTRACT: Active methodologies are increasing in the teaching and learning process. This scenario, as a result of the insertion of ICT in the classroom. In this review, Problem-Based Learning was observed, which has goals of teaching about how and for what purpose water, effluent and sludge treatment is used. Active methodologies contribute to the training process of both the student and the teacher.

KEYWORDS: Teaching-learning. Active methodology. Sciences teaching. Problem based learning.

O professor deve não só trabalhar na teoria com os seus alunos, mas também nas práticas

${ }^{1}$ Faculdade Anhanguera de Bauru (FAB), Bauru - SP - Brasil. Discente do curso de Pedagogia. E-mail: dayquirino@outlook.com.br 
para que os mesmos fiquem curiosos e ansiosos para começar a investigar, descobrir e compreender como acontece o tratamento de água, efluente e lodos.

Portanto, as Instituições de Ensino não dispõem metodologias além das salas de aula (fora da unidade), para exercer um ensino-aprendizagem na base prática, só acontece a relação de professor-aluno dentro da escola e/ou universidade.

Todavia, os alunos que estão a ajudar o professor com diversas metodologias, enquanto desenvolvem o aprendizado com as variadas disciplinas.

Existem diversas metodologias que os alunos estão utilizando, como por exemplo, observação do problema, discussão, teorização, formulação de solução e aplicação da realidade.

A Aprendizagem Baseada em Problemas pode ser tão difícil para os alunos, que acaba se mostrando como deficiência, assim os autores citam:

\section{As deficiências encontradas pelo grupo e com foco na solução do problema central, já identificado, gera uma etapa de estudos autodirigidos. Esses processos são planejados de forma que os alunos sejam orientados na busca de novos conhecimentos científicos necessários para resolver o problema atribuído (HOLLENBECK, 2008, p. 04).}

Mesmo com essas "deficiências", os alunos não desistem de pesquisar, teorizar e praticar o conhecimento para que consigam executar o problema com êxito.

Desse modo, os alunos acabam por encorajar e construir um conhecimento e aprendizado mais profundo.

Assim, os alunos precisam desenvolver e compreender 8 etapas para ter um problema executado: conteúdos, necessidade de conhecer, questão norteadora, voz e escolha do estudante, competências do século XXI, aprofundamento da questão, crítica e revisão-exposição do trabalho ao público.

Com isso, os alunos trabalharam com o professor para desenvolver esse método de Tratamento de Água, Efluentes e Resíduos na Instituição de Ensino de Goiás e com essa metodologia foram ganhando conhecimento e desenvolvendo a relação de ensinoaprendizagem.

Para que tudo fosse bem trabalhado, foi necessário que os alunos se adaptassem com o modelo da escola e que fossem atrás de pessoas para entrevistá-las sobre o tratamento da água, de efluentes e de resíduos, para que depois pudessem analisar cada opinião coletada e executar a metodologia do problema.

Diante do problema de que as Instituições de Ensino não dispõe metodologias além das salas de aula (fora da unidade), a professora e os alunos buscaram se aprofundar na pesquisa, 
através de vídeos, visitaram diversos lugares para compreender melhor a importância da água, a importância do tratamento, fizeram uso de textos de diversos autores, etc.

Depois dessa experiência prática que todos tiveram, foi feito uma avaliação formativa e somativa em conjunto (todos unidos), para que pudessem ver o desempenho em grupo e/ou individual, e cada um teve uma nota, que variou bastante, desde baixa ( 1 a 3 ) até excelente $(4,5$ a 5).

Portanto, depois dessa avaliação a professora percebeu o interesse e a curiosidade dos alunos na questão do tratamento da água e do esgoto, também notou através das entrevistas feitas pelos mesmos, que as pessoas não tem noção do que seria um tratamento de esgoto e/ou o que seria um saneamento básico.

Desse modo, a professora entendeu que a Pedagogia precisa aprofundar mais nos assuntos sobre o saneamento básico e sobre o tratamento do esgoto, por serem de suma importância e envolverem a política local, porém, os autores citam:

Essa metodologia pode ser definida como uma abordagem orientada para a investigação, por partir de questões (levantadas pelos alunos após apresentação do cenário) e envolver a procura de soluções (BARROWS, 1996; BORDENAVE; PEREIRA, 1980, p. 08).

Com o uso dos vídeos, a professora observou que os alunos aprenderam mais a relacionar a teoria com a prática, e descobriu diversos assuntos históricos, científicos e culturais na zona urbana da cidade de Paris.

Assim, com os conhecimentos do tratamento da água e do esgoto, os alunos desenvolveram mais as suas concepções cognitivas, com a capacidade de pensar e de absorver conceitos para ter sucesso na execução do problema.

Depois, os alunos perceberam que com a utilização dessas metodologias as notas das avaliações melhoraram $(4,4)$, que tiveram sucesso no ensino-aprendizagem $(4,2)$, que compreenderam a importância de trabalhar em grupo (4), que o desenvolvimento do tema também era de suma importância $(3,8)$ e, mesmo com a falta de apoio familiar, aprenderam a ter os seus próprios conceitos.

Com o passar do tempo, os mesmos observaram que a discussão do tema foi aumentando a nota da avaliação, como por exemplo, 4,5; e que o tema teve inter-relação com as variadas disciplinas, porém, teve também uma nota (4), pois compreenderam a importância de se resolver uma aprendizagem baseada em problema.

Com o passar do tempo, as avaliações individuais e/ou em grupos foram variando $(4,6 / 3,7)$, pois os alunos acabam tendo dificuldades para compreender o entendimento e 
conhecimento de cada colega, como demonstra a citação dos autores:

O aprendizado é tão pessoal quanto uma impressão digital, uma vez que diferentes pessoas aprendem de maneiras diferentes. Assim, percebese que cada pessoa tem um ritmo de aprendizagem diferente e um grau de atenção diferente (CHAVES, 2000, p. 10).

Desse modo, o desempenho dos alunos foi bem satisfatório para a Instituição de Ensino, que chegou a ter a nota 4, porém, a utilização das metodologias deu a liberdade e responsabilidade para cada indivíduo, motivadas pelo professor, pois

é exigido do educador uma mudança do papel de informante para o de construtor de conhecimentos e estimulador da produção dos próprios alunos; não basta o domínio do conhecimento amplo e atualizado; é necessário saber produzir o conhecimento e o que se ensina (HAGUENAUER, 2005, p. 11).

Sendo assim, a nota dos alunos em participação e foco chegou a 4,4, e perceberam que a troca de experiência e a relação de professor-aluno estava trazendo benefício para diversas interdisciplinaridades, para liberdade e conhecimento dos alunos.

Portanto, a Instituição de Ensino fez uma lista de notas desde metodologia até avaliação do desempenho individual ou em grupo, por exemplo: Participação no processo de ensinoaprendizagem (4,2); Interação entre os componentes do grupo (4); Compreensão dos temas abordados $(3,8)$; Ferramentas de aprendizagem utilizadas ( ntrevista, vídeo, visitas, seminários, construção do protótipo) (4,4); Capacidade de aprofundamento nos temas abordados (4); Relação entre os temas abordados com o mundo real (4,5); Interação do tema abordado com as diferentes disciplinas do curso (4); Desempenho na realização de todas as etapas do projeto $(3,8)$; Desempenho dos demais componentes do grupo nas etapas do projeto $(3,7)$; Motivação para a realização das atividades (4); Participação na construção do protótipo $(4,4)$; Apresentação do protótipo $(4,6)$.

Essas notas possibilitaram aos alunos continuar a desenvolver a aprendizagem baseada em problema, para que as habilidades fossem trabalhadas, como a comunicação e a discussão.

Durante o desenvolvimento dessa metodologia, os alunos perceberam diversos pontos negativos e positivos, porém, observaram o caráter da execução científica, e compreenderam a importância do andamento do ensino-aprendizagem, que é de suma importância para a sua formação; e entenderam que o ser humano precisa passar por variados problemas, para que se aprofundem mais para o amadurecimento cognitivo acontecer.

Essa metodologia além de ter desenvolvido curiosidade, responsabilidade e 
conhecimento, também desenvolveu criatividade e autoconfiança em cada aluno, porém, todos precisam aceitar e praticar essas habilidades ganhas, mantendo-as afiadas mesmo na vida pós formação.

Enfim, essa metodologia chamada de aprendizagem baseada em problema, que envolveu diversas disciplinas, mostrou a curiosidade, a responsabilidade, o conhecimento, a criatividade e a autoconfiança de cada aluno, para aprender a desenvolver a habilidade de trabalhar em grupo e para perceber que existe o ensino-aprendizagem quando fazem a relação de professor-aluno e ou de aluno para aluno, que observaram, entenderam, compreenderam e praticaram como são feitos o tratamento da água e do esgoto.

\section{REFERÊNCIA}

MACHADO, Regina; BOHM, Giani; BOHM, Emerson. Aprendizagem baseada em problemas: um estudo de caso na disciplina de tratamento de água, efluente e lodos. Revista Ibero-Americana de Estudos em Educação, Araraquara, v. 13, n.4, out./dez., 2018. ISSN 1982-5587. DOI: 10.21723/riaee.unesp.v13.n4.out/dez.2018.10497 Disponível em: https://periodicos.fclar.unesp.br/iberoamericana/article/view/10497/7704. Acesso em: 06 mar. 2018.

\section{Como referenciar este artigo}

QUIRINO, Daiane Sthéfani. Metodologias ativas: um relato sobre aprendizagem baseada em problemas no ensino de ciências. Temas em Educ. e Saúde, Araraquara, v. 15, n. 1, p. 175-79, jan./jun., 2019. e-ISSN 2526-3471. ISSN 1517-7947. DOI: 10.26673/tes.v15i1.12773

Submetido em: 20/03/2019

Aprovado em: 05/04/2019 